Proceedings of SALT 31: 061-081, 2021

\title{
Modality in the nominal domain: Yalnhej DPs in Chuj*
}

\author{
Luis Alonso-Ovalle \\ McGill University
}

\author{
Justin Royer \\ McGill University
}

\begin{abstract}
How do modal expressions determine which possibilities they invoke? Do they do it the same way across categories? Recent work proposes that modal auxiliaries project the domain of possibilities that they quantify over from an event variable, which can get different values in different syntactic positions (Hacquard 2006, 2009, 2010, see also Kratzer 2013). Based on the behaviour of the Spanish random choice indefinite uno cualquiera, Alonso-Ovalle \& Menéndez-Benito (2018) conclude that the same strategy is available for modal indefinites. This paper brings evidence from Chuj, an understudied Mayan language, which supports this conclusion further. We focus on yalnhej DPs, a type of quantifier that makes a non-upper bound existential claim and contributes a modal component with a flavour that depends on syntactic position.
\end{abstract}

Keywords: free choice items, random choice, epistemic indefinites, Chuj, Mayan

\section{Introduction}

Modality spans across categories (Kratzer 1981), but most work has traditionally focused on the verbal domain. Recently, however, modal expressions in other categories have started to receive attention (see e.g., Arregui, Rivero \& Salanova 2017), leading to several questions about the crosscategorial behaviour of modality. For instance, focusing on DPs, we might ask:

\section{Q1. What types of modal flavour can DPs express?}

Q2. How is the modal flavour of modal DPs determined?

In the verbal domain, modals can express a wide range of flavours. The extent to which the modal flavours of modal DPs parallel those found in the verbal domain is

* Thanks to our generous language consultants: Matal Torres, Matin Pablo, Reinalda Domingo, Xuwan Gómez, Agenor Torres País, Mach'ol Torres, Mekel Torres Torres, Petul Torres, Petul (Tigo) Torres País, Rogelio Torres, Yun Torres, Elsa Torres Velasco, Xun Torres Velasquez, Ana Velasco, and Heb'in Velasco. A special thanks to Matin Pablo and Matal Torres for their valuable work and for volunteering insightful scenarios. The Social Sciences and Humanities Research Council of Canada provided financial support through an Insight Grant (Modality across Categories, 435-2018-0524). Our names are listed in alphabetical order 
an open question. Likewise, in the verbal domain, modal flavour seems to correlate with syntactic position: epistemic modals seem to scope higher than circumstantial ones (Brennan 1993; Hacquard 2006). It remains to be determined whether the syntactic position of modal DPs also affects their possible interpretations and, if so, whether modal flavours are determined uniformly across categories.

Within the class of modal DPs, modal indefinites have been reasonably well studied (see Alonso-Ovalle \& Menéndez-Benito 2015, and references therein), and are therefore well suited to make progress in establishing crosscategorial comparisons. This paper looks at modal indefinites with the aim of making progress on the questions posed above. We focus on yalnhej DPs, a type of modal indefinite found in Chuj, an understudied Mayan language spoken by approximately 70,000 speakers in Guatemala and Mexico (Piedrasanta 2009; Buenrostro 2013). ${ }^{1}$

Like other modal indefinites, yalnhej-DPs convey (a) existential quantification over individuals, and (b) a modal component. The sentence in (1), for instance, conveys (a) that Xun bought a book or a group of books, and (b) that he could have bought any book or group of books.

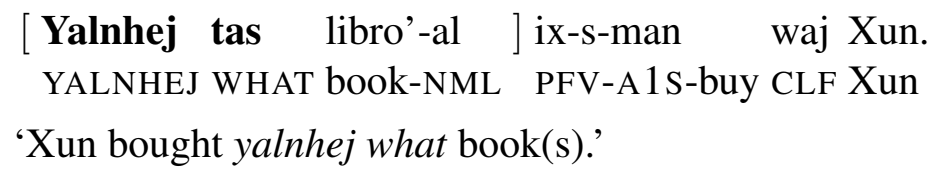

Yalnhej DPs can convey two modal flavours. The first type, which we call 'random choice modality' (Alonso-Ovalle \& Menéndez-Benito 2018), conveys information about the intentions of an agent: (1) can convey that Xun bought a book at random. The second type conveys information about what an individual believes: (2) indicates (a) that a person or group of people danced, and (b) that the speaker does not know who danced, leaving open the possibility that everyone danced.

$$
\begin{aligned}
& \text { [Yalnhej mach ] ix-chanhalw-i t'a k'inh. } \\
& \text { YALNHEJ who PFV-dance-IV PREP party } \\
& \text { 'Yalnhej who danced at the party.' }
\end{aligned}
$$

1 Our data come from two sources: i) original fieldwork conducted with speakers of the San Mateo Ixtatán variant of Chuj, collected in communities in Guatemala and Mexico, and with two consultants in Montreal; and ii) the corpus of narratives presented in Mateo Pedro \& Coon 2017. We used a hypothesis-driven fieldwork methodology (Matthewson 2004, Davis, Gillon \& Matthewson 2014).

Throughout the paper, we will not attempt to provide a direct translation of our example sentences, since there are not direct equivalences, and rely, most of the time, on indirect paraphrases. We use the following abbreviations in glosses: A: "Set A" (ergative/possessive); ALGúN: Spanish algún; B: "Set B" (absolutive); CLF: noun classifier; CUALQUIERA: Spanish cualquiera; DEM: demonstrative; DTV: derived transitive status suffix; FOC: focus marker; INDF: indefinite; NML: nominal suffix; IPFV: imperfective; IRGEND: German irgend; IV: intransitive status suffix; PFV: perfective. 
Modality in the nominal domain

Other modal indefinites express these modal flavours, but yalnhej-DPs exemplify new typological possibilities. For one, this paper shows that the modal component of yalnhej-DPs (under any of its flavours) is truth-conditional. In this respect, yalnhejDPs pattern with other modal indefinites that also convey random choice modality, like Spanish uno cualquiera (Alonso-Ovalle \& Menéndez-Benito 2018), but contrast with Spanish algún (Alonso-Ovalle \& Menéndez-Benito 2010) or German irgendein (Kratzer \& Shimoyama 2002), whose modal component is not truth-conditional, and possibly also with the modal component of English wh-ever free relatives under their epistemic interpretation (von Fintel 2000). Also, unlike what is the case with other modal indefinites, the existential claim made by yalnhej-DPs is not upper-bounded: the sentence in (2), for instance, is compatible with all people having danced (and the speaker knowing that). Finally, the type of modality that yalnhej DPs express depends on their syntactic position, making them an ideal testing ground for Q2 above. As objects of volitional verbs, as in (1), yalnhej-DPs can convey either random choice modality or epistemic modality, but as (non passive) subjects, as in (2), they can only convey epistemic modality. Recent work proposes that modal auxiliaries project their domains of quantification from an event or an entity (a 'modal anchor') (Hacquard 2006, 2009, 2010; Kratzer 2013). Under Hacquard's proposal, the modal anchor of modal auxiliaries is an event variable, which can get different values in different positions, explaining the correlation between position and interpretation. We propose that the same is true for yalnhej DPs. This follows Alonso-Ovalle \& Menéndez-Benito's analysis of the random choice component of uno cualquiera. However, as we will see, yalnhej-DPs impose less restrictions on their anchors than modal indefinites like uno cualquiera, and can thus express more modal flavours.

The paper is organized as follows: section 2 lays out the main empirical generalizations, section 3 presents the analysis, and section 4 concludes.

\section{Yalnhej DPs}

\subsection{Background}

Chuj is a head-marking language and exhibits no case morphology on nominals. Its basic word order is VOS, as illustrated in (3): ${ }^{2}$

$$
\begin{aligned}
& \text { Ix-y-il [Obj winh icham }]\left[\begin{array}{l}
\text { Subj ix ix } \\
\text { PFV-A3-see }
\end{array}\right. \text { CLF elder } \\
& \text { CLF woman }
\end{aligned}
$$

'The woman saw the elder.'

2 Hopkins 1967, 2021, Maxwell 1981, García Pablo \& Domingo Pascual 2007, Buenrostro 2013, and Royer, Mateo Pedro, Carolan, Coon \& Torres to appear are useful resources on the grammar of Chuj. 
While VOS is the basic word order, Chuj arguments are frequently instantiated in a preverbal position. For instance, quantificational DPs, whether subjects or objects, are generally preferred preverbally, as seen in (4). ${ }^{3}$

a. [ Masanil heb' winh winak ] ix-il-an nok' tz'i' . all PL CLF man PFV-see-AF CLF dog 'All of the men saw / cared for the dog.'

b. ??Ix-y-il nok' tz'i' [ masanil heb' winh winak ]. PFV-A3-see-AF CLF dog all PL CLF man

Other DP expressions, such as 'only' DPs (5) and wh-phrases in questions (6), obligatorily appear preverbally (see Coon, Baier \& Levin 2021 for discussion). ${ }^{4}$

a. [Ha=nhej waj Xun ] ix-in-il-an-i. FOC-only CLF Xun PFV-B1S-see-AF-IV

'Only Xun saw me.'
b. *Ix-in-y-il
[ nhej waj Xun ].
PFV-B 1S-A3-see
only CLF Xun

(6)
a. Mach ix-il-an winh icham.
who PFV-see-AF CLF elder
'Who saw the elder?'
b. Tas (libro'al) ix-a-man-a'. what (book) PFV-A2s-buy-TV
'What (book) did you buy?'
c. Mach libro ix-a-man-a'. which book PFV-A2S-buy-TV 'Which book did you buy?'

In the absence of explicit plural marking, wh-phrases are semantically number neutral: (6a) can be given any of the answers in (7), and (6b) and (6c) any of the answers in (8). ${ }^{5}$
a. Kixtup.
a. This book.
b. Kixtup, Xun, and Malin.
b. This book and that book.

3 As in other Mayan languages (Aissen 2017), left-displaced transitive subjects trigger a particular type of verbal inflection glossed "AGENT FocUs (AF)".

4 Kotek \& Erlewine (2019: 70-71) report the possibility of wh-in situ for echo questions, but we have not been able to corroborate these judgments. Note, though, that certain $w h$-expressions can be used as $w h$-indefinites, as also reported by Kotek \& Erlewine (2019) (see also Royer 2020). In such cases, wh-words are possible in postverbal positions.

5 Wh-phrases can be pluralized with the suffix -tak (Royer 2020, Buenrostro to appear), in which case they only tolerate plural answers. 
Modality in the nominal domain

\begin{tabular}{lll}
\hline & wh-expression & modal DP \\
\hline 'what' & tas $(+\mathrm{N})$ & $\sqrt{ }$ yalnhej tas $(+\mathrm{N})$ \\
'who' & mach & $\sqrt{ }$ yalnhej mach \\
'which' & mach $(+\mathrm{N})$ & $\sqrt{ }$ yalnhej mach $(+\mathrm{N})$ \\
'where' & b'aj/b'ajt'il/ajt'il & $\sqrt{ }$ yalnhej b'aj/b'ajt'il/ajt'il \\
'when' & b'ak'inh & $\sqrt{ }$ yalnhej b'ak'inh \\
'how' & tas + light verb & $\sqrt{ }$ yalnhej tas + light verb \\
'how much' & jantak & $\mathbb{\checkmark}$ yalnhej jantak \\
'how many' jantak/jay-NUM.CLF & $\mathbb{\checkmark}$ yalnhej jay-NUM.CLF \\
\hline 'why' & tas yuj & $\boldsymbol{X}$ yalnhej tas yuj \\
\hline
\end{tabular}

Table 1 List of wh-expressions and corresponding yalnhej forms (Royer 2020)

\subsection{Yalnhej DPs: Morphosyntactic distribution}

Yalnhej-DPs are composed of the complex morpheme yalnhej and a wh-phrase, either simplex, as in (9), or complex, as in (10):

(9)
yalnhej mach $]$
(10) [yalnhej tas libro'-al ] YALNHEJ WHAT book-NML

Table 1 shows that all types of wh-expressions can combine with yalnhej to form a modal DP (see Royer 2020, §4.1.3), with only one exception: tas yuj 'why'.

Yalnhej DPs pattern with wh-items in that, in the absence of explicit plural marking, they are number neutral: the sentence in (11), for instance, can describe a situation where Malin read only one book, but also one where she read several.

[Yalnhej tas libro'-al ] ix-y-awtej ix Malin YALNHEJ WHAT book-NML PFV-A3-read CLF Malin $\approx$ 'Malin read yalnhej what book.'

We describe yalnhej as a 'complex' morpheme. This is so because, as a free morpheme, with aspect marking, yal functions as a modal auxiliary, as seen in (12) (Buenrostro 2009, Kotek \& Erlewine 2019). The morpheme nhej, on the other hand, is usually glossed as 'only' when it appears on its own, as in (5a) above.

$$
\begin{aligned}
& \text { Ix/tz/ol-yal ha-lolon w-et'ok. } \\
& \text { PFV/IPFV/PROSP-MODAL A2S-speak A1 S-with }
\end{aligned}
$$

'You were/are/will.be allowed to speak with me.' 
Yet, it is unclear at the present stage whether there are truly two interpretable pieces to consider. For one, the possibility of inserting material between yal and nhej is highly restricted; only second position clitics like $x o$ 'now' can do so:

$$
\begin{aligned}
& \text { [ Yal-xo-nhej b'aj ] tz-k-il juntzanh y-ik mejikano. } \\
& \text { YAL-ADV.now-NHEJ where IPFV-A1P-see some A3-by mexican } \\
& \approx \text { 'Now we see Mexican things (anywhere).' }
\end{aligned}
$$

Second, the segment yal is never inflected within yalnhej DPs, and yalnhej-DPs do not pattern in distribution with only phrases (or interrrogatives): those must appear preverbally, but yalnhej-DPs pattern with quantificational DPs in merely showing a preference for appearing in a preverbal position. ${ }^{6}$

$$
\begin{aligned}
& \text { a. [ Yalnhej tas ] ol-s-man waj Xun. } \\
& \text { YALNHEJ what PROSP-A1s-buy CLF Xun } \\
& \text { 'Xun will buy anything.' } \\
& \text { b. ?Ol-s-man [ yalnhej tas ] waj Xun. } \\
& \text { PROSP-A1s-buy YALNHEJ what CLF Xun }
\end{aligned}
$$

For now, we will leave open the issue of the internal compositionality of yalnhej DPs, glossing the combination of yal and nhej as a unit.

\subsection{Interpretation: Subjects vs. objects}

While typically fronted, the modal meaning of yalnhej-DPs depends on their base position. As anticipated, yalnhej-DPs contribute epistemic modality in subject position (as external arguments). For instance, sentence (15) could be uttered in context (16a) where (i) the speaker knows that some (but not all) people danced, but (ii) the speaker does not know exactly who danced. However, it cannot be used in context (16b) where (i) the speaker knows that some (but not all) people danced, and (ii) the speaker knows who did.

[ Yalnhej mach ] ix-chanhalw-i t'a k'inh.

YALNHEJ who PFV-dance-IV PREP party

'A person or group of people danced, I don't know who (maybe all did).'

a. Speaker was at a party; they know for a fact that not everyone danced, but couldn't really tell you who exactly danced.

$(15)=\checkmark$

6 Out of a scale from 1 to 5, 1 being ungrammatical and 5 being perfectly natural, the speakers we consulted judged (14a) as 5/5 and (14b) as 3/5. Yalnhej-DPs can also appear right-dislocated, leading to a VSO word order. In such cases, the speakers judge the sentence as perfectly natural (i.e. 5/5). 
Modality in the nominal domain

b. Only Kixtup and Xun danced at the party. Speaker knows this. $\quad(15)=\boldsymbol{X}$

The sentence in (15) can also be used in the context in (17), where the speaker knows that everybody danced. The comment in (18), which we received from one consultant about (15), highlights this.

(17) Context 3: Speaker was at a party; they know everyone danced.

$(15)=\checkmark$

(18) "When you hear (15), you could conclude that just some people danced (and the speaker doesn't know who), or simply that everybody danced."

Transitive subjects give rise to the same type of interpretation: the sentence in (19) is felicitous in the two first contexts in (20), but infelicitous in the third.

(19) [Yalnhej mach ] ix-chi'-an chi'b'ej t'a k'inh.

YALNHEJ who PFV-eat-AF meat PREP party

'A person/some people (maybe all) ate meat at the party.'

(20) a. There was a town party, and meat was served to everyone who wanted it. Speaker knows that at least some people ate meat, but he couldn't tell who.

$(19)=\checkmark$

b. There was a town party; no one in town is a vegetarian, so speaker thinks everyone ate meat.

$(19)=\checkmark$

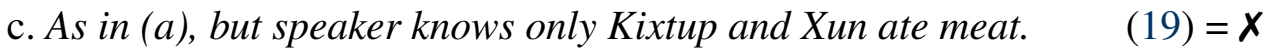

Like in subject position, yalnhej-DPs in object position can convey epistemic modality. For example, the sentence in (21) is appropriate in the context in (22a), but not in a context where the speaker knows which dish(es) Xun liked and knows that he didn't like all of them (22b). Though not illustrated with context here, note that $(21)$ is also consistent with the speaker knowing that Xun liked all dishes. ${ }^{7}$

[ Yalnhej tas tekal ] ix-s-nib'-ej waj Xun. YALNHEJ what dish PFV-A3-like-DTV CLF Xun

'Xun liked some dish or some group of dishes, maybe all dishes.'

7 Speakers can use yalnhej DPs to pretend to be ignorant, while they are not truly so, replicating the 'teasing' effects described for English whatever in von Fintel 2000:

(i) a. Your child bought lots of candy, even though you told him not to. You ask him what he bought. He answers:

b. [ Yalnhej tasi ] <ix-in-man-a' >

YALNHEJ what PFV-A1s-buy-TV

$\rightsquigarrow$ 'Something, and anything is a possibility.' 
a. Xun went to a market and tried a few dishes. Speaker knows that Xun liked at least one dish (maybe more), but they're not sure which.

$(21)=\checkmark$

b. Xun went to a market, tried a few dishes, but didn't like them all. Speaker knows exactly which dishes Xun liked: soup and tamales.

$(21)=\boldsymbol{X}$

In the object position of volitional transitive verbs, yalnhej DPs can also convey random choice modality. The sentence in (23) can convey (i) that Xun bought a book, and (ii) that he was indifferent about what book to buy. The sentence can felicitously describe the context in (24a), but not the one in (24b).

[ Yalnhej tas libro'al] ix-s-man waj Xun.

YALNHEJ what book PFV-A3-buy CLF Xun

'Xun bought a random book / some random books.'

a. Xun wanted to read, but didn't have any specific book in mind. He went to the bookstore and bought one at random.

$(23)=\checkmark$

b. Xun wanted to read a specific book, the Popol Wuj, went to the bookstore and bought it.

$(23)=\boldsymbol{X}$

As was the case with the epistemic component, under the random choice interpretation, the sentence in (23) can describe a situation where all individuals of the relevant type satisfy the existential claim.

(25) Xun is very wealthy, and a bit insane. He goes to a bookstore, and he starts buying books indiscriminately, to the point where he ends up buying all books.

$(23)=\checkmark$

In (23), yalnhej-DP is in the object of a volitional predicate. This distinction is important, since with non-volitional predicates, only epistemic interpretations are possible. The sentence in (26), for instance, can only convey that either the speaker does not know which dish Xun liked, or that he liked them all.

[Yalnhej tas tekal] ix-s-nib'-ej waj Xun. YALNHEJ what dish PFV-A3-like-DTV CLF Xun

'Xun liked some dish(es) or other.' / not: 'Xun liked a dish at random.'

The interpretation of yalnhej-DPs is reminiscent of the interpretation of English wh-ever free relatives, which can also convey agent indifference or speaker ignorance (von Fintel 2000), a parallelism that is strengthened by the observation in Table 1 that neither yalnhej-DPs nor wh-ever free relatives have why forms. There are, however, reasons not to equate yalnhej-DPs with wh-ever free relatives. Unlike wh-ever free relatives (Jacobson 1995), yalnhej-DPs do not convey maximality: the sentence in (27) (but not (28)) can felicitously describe the context in (29). ${ }^{8}$

8 The same is true for the epistemic interpretation: (i) can describe the context in (ii). 
Modality in the nominal domain

[ Yalnhej tas yamk'ab'il] ix-s-yam ix. YALNHEJ what tool PFV-A3-grab she

'She grabbed some tool(s) at random.'

(28) She grabbed whatever tools were in the toolbox.

(29) There are ten tools in a box in front of Malin. Malin doesn't need one in particular. She grabs only three at random.

$(27)=\boldsymbol{J} /(28)=\boldsymbol{X}$

\subsection{Status of modal component}

The modal component of some previously identified modal indefinites, such as Spanish algún or German irgendein, has been argued to be an implicature (Kratzer \& Shimoyama 2002; Alonso-Ovalle \& Menéndez-Benito 2011), since, as illustrated below, it disappears in downward entailing contexts.

(30) Si Juan compró algún libro, hablaré con su padre.

if Juan bought ALGÚN book, I will talk to his father

'If Juan bought a book / books, I will talk to his father.' / Not: 'If Juan bought a book / books and I don't know which one(s) ...'

(Spanish)

(31) Hans hat nie irgend-ein Buch gekauft.

Hans has never IRGEND-a book bought.

'Hans never bought any book.' / Not: 'It was never the case that Hans bought a book and I didn't know which book.' (German: Buccola \& Haida 2017)

In contrast, the modal component of other modal indefinites, such as Spanish uno cualquiera, survives embedding under a downward entailing environment (32), and has been argued to be truth-conditional (Alonso-Ovalle \& Menéndez-Benito 2011).

(32) Nadie cogió un libro cualquiera.

no.one grabbed a book CUALQUIERA

'Nobody grabbed a book at random.'

(Spanish)

In the case of wh-ever phrases: the modal component projects like a presupposition when it is epistemic, but not when it conveys agent indifference (von Fintel 2000). ${ }^{9}$

(i) [Yalnhej tas ix-s-b'o' ix Telex ewi ], ix-y-ab'lej ix Xuwan. YALNHEJ what PFV-A3-make CLF Telex yesterday PFV-A3-eat CLF Xuwan

$\rightsquigarrow$ 'Xuwan ate things that Telex made yesterday, but I don't know what exactly.'

(ii) Telex cooked 10 meals yesterday, five of which Xuwan tasted. The speaker doesn't know what meals Telex cooked.

9 Though see Condoravdi 2015 for doubts about the presuppositional status of wh-ever free relatives. 
The modal component of yalnhej-DPs is truth-conditional. The random choice component survives embedding under negation and in the antecedent of conditionals, as seen in (34b) and (35b), judged as felicitous continuations of context (33).

(33) You're playing a board game, and as part of the rules you must first pick one card at random (with your eyes closed). Some cards give you a clear advantage, others put you at disadvantage. If you don't respect this rule, you're cheating...

a.... Xun didn't close his eyes and selected a specific card, that of course, gave him an advantage. I ask you, how did Xun cheat?

b. Man yalnhej tas karta-ok laj ix-s-yam winh.

NEG YALNHEJ what card-IRR NEG PFV-A3-grab CLF

'He didn't grab a card at random.'

a.... You're explaining how not to cheat, using Xun as an example player, you say:

b. Tato yalnhej tas karta'-il ix-s-yam waj Xun, wach' winh. if YALNHEJ what card-NML PFV-A3-grab CLF Xun, good CLF 'If Xun grabs a card at random, he's playing well.'

Similarly, the epistemic modal component survives embedding under negation (36a), as indicated by the possible continuation in (36b), and under the antecedent of conditionals (37b).

a. Maj s-nib'-ej laj waj Xun [ yalnhej tas wa'el-al ]. NEG.PFV A3-like-DTV NEG CLF Xun YALNHEJ what dish-NML 'It's not the case that Xun liked some dish and I don't know what dish.'

b. Ha tas maj s-cha laj s-k'o'ol masanil chi', ha-chi' FOC what NEG.PFV A3-like NEG A3-stomach all DEM FOC-DEM ix-y-ab'l-ej winh. PFV-A3-eat-DTV PRON

'The dish that everybody didn't like, that's the one he ate.'

(37) a. You're a firefighter, so you know how to stop fire. If you know where the fire is coming from, you don't get worried. You only get worried if you do not know where the fire is coming from.

b. Tato tz'-och k'ak [ t'a yalnhej b'ajt'i'il ], tz-in-och If PFV-enter fire PREP YALNHEJ where IPFV-B 1S-enter hin-k'o'ol-al y-u'uj. A3-stomach-NML A3-for

'If fire starts in some place (and I don't where), I get worried.' 
Modality in the nominal domain

To summarize: we have shown that yalnhej-DPs make an existential claim and contribute an at-issue modal component. While they can contribute either epistemic or random choice modality as objects of volitional verbs, they can only contribute epistemic modality in subject position.

\section{A modal quantifier}

Building on the analysis of uno cualquiera presented in Alonso-Ovalle \& MenéndezBenito 2018, we propose, as schematized in (38), that yalnhej-DPs combine with an event argument and convey as part of their truth-conditions i) a non-modal existential claim, and ii) a modal component that hardwires a free choice effect and states, roughly, that every individual in the extension of the wh-phrase is involved in the relation expressed by the VP in some world in a domain of accessible worlds. ${ }^{10}$

$$
\begin{aligned}
& \llbracket[\text { yalnhej wh-NP }] e_{1} \rrbracket^{g}=\lambda P_{\langle e,\langle v, s t\rangle\rangle} \cdot \lambda e \cdot \lambda w . \\
& \underbrace{\exists x\left[\begin{array}{l}
P_{w}(x)(e) \& \\
\llbracket w h-N P \rrbracket(x)(w)
\end{array}\right]}_{\text {existential component }} \& \underbrace{\forall y\left[\begin{array}{l}
\llbracket \text { wh-NP } \llbracket(y)(w) \rightarrow \\
\exists w^{\prime} \in f\left(\mathbf{e}_{\mathbf{1}}\right) \exists e^{\prime}\left[e^{\prime} \approx e \& P_{w^{\prime}}(y)\left(e^{\prime}\right)\right]
\end{array}\right]}_{\text {modal component }}
\end{aligned}
$$

We note two correlates of the high quantificational type that we assign to yalnhejDPs: (i) as already discussed, yalnhej-DPs pattern with wh-phrases and other quantificational elements in showing a preference for appearing in a preverbal position, and (ii) yalnhej-DPs are ruled out in predicative positions, as shown below: ${ }^{11}$

$$
\begin{aligned}
& \text { a. *Yalnhej tas anima'-il waj Xun. } \\
& \text { YALNHEJ what person-NML CLF Xun }
\end{aligned}
$$

b. *Yalnhej b'ajt'il jun chonhab' tik.

$$
\text { YALNHEJ where one village DEM }
$$

The upcoming discussion will mostly focus on the modal domain of yalnhejDPs. We hypothesize that the set of accessible worlds that yalnhej-DPs range over is determined in much the same way it is determined for modal auxiliaries. Recent work defends that modal auxiliaries project their domain of quantification from an

10 We will assume explicit quantification and abstraction over worlds and events in the object language. We use boldface type to mark the value of a variable. We assume that VPs denote relations between individuals, events and worlds (have type $\langle e,\langle v, s t\rangle\rangle$, using $v$ as the type of events), and we give $w h$-NPs a predicative type $(\langle e, s t\rangle)$, assuming that the extension of $w h$-NPs that are not inflected in the plural is closed under sum formation. " $\approx$ " conveys that $e$ and $e^{\prime}$ have the same spatiotemporal location. We omit the possible requirement that $e^{\prime}$ shares other event participants with $e$.

11 According to (38), yalnhej DPs operate over functions of type $\langle e,\langle v, s t\rangle\rangle$. We assume that this blocks them from copular sentences. See Poole 2017 against type shifting traces to predicative type. 
eventuality (their 'modal anchor'; Hacquard 2006, 2009, 2011; Kratzer 2013). We assume that yalnhej-DPs project their modal domain out of the value of an event variable, via a domain fixing function $f$ that maps events to sets of possible worlds, as in Alonso-Ovalle \& Menéndez-Benito 2018. The modal flavour of yalnhej-DPs depends on which type of event their modal domain projects from. Possible anchors and projection modes differ depending on syntactic position, as we discuss next.

\subsection{Random choice modality}

We follow Alonso-Ovalle \& Menéndez-Benito (2018) in assuming that random choice interpretations correspond to modal projection from the type of event described by the VP, as in the LF of (40a) in (40b) - with explicit quantification and abstraction over event and world variables-where the modal anchor of the yalnhej DP is co-bound with the event argument of the VP.

a. [Yalnhej tas libro'al ] ix-s-man waj Xun.
YALNHEJ what book PFV-A3-buy CLF Xun

'Xun bought a random book / group of books.'

b. $\lambda w_{1} \exists_{e}$ Xun $\left[{ }_{v}\right.$ Agent $\left[{ }_{\mathrm{vP}} \lambda e_{1}\left[\left[\left[\right.\right.\right.\right.$ yalnhej what book $\left.e_{1}\right] \lambda x_{1}$ bought $\left.\left.\left.\left.t_{1}\right] e_{1}\right] w_{1}\right]\right]$

In (40b) yalnhej what book, when combined with its modal anchor, operates over the relation in (41), and returns a relation between events and worlds (type $\langle v, s t\rangle)$. After saturation with an event and a world variable, and after abstraction over the event variable, we get a property of events, which combines with the agent via Event Identification (Kratzer 1996). Ignoring temporal and aspectual information, and assuming external Existential Closure over the event argument, the LF in (40b) denotes the proposition in (42), which conveys i) the existence of an event $\mathbf{e}$ of buying one or more books by Xun, and ii) information about a set of possibilities that project from $\mathbf{e}$.

$$
\begin{aligned}
& \llbracket \lambda x_{1} \text { bought } t_{1} \rrbracket=\lambda x_{e} \lambda e_{v} \lambda w_{s} \cdot \mathrm{BUY}_{w}(x)(e) \\
& \lambda w . \exists e[\underbrace{\exists x\left[\begin{array}{l}
\mathrm{BUY}_{w}(x)(e) \& \\
{ }^{*} \operatorname{BOOK}_{w}(x) \& \\
\operatorname{AGENT}(\mathrm{XUN})(e)
\end{array}\right]}_{\text {existential component }} \& \underbrace{\forall y\left[\begin{array}{c}
\mathrm{BOOK}_{w}(y) \rightarrow \exists w^{\prime} \in f(e) \\
\exists e^{\prime}\left[\begin{array}{l}
e^{\prime} \approx e \& \\
\operatorname{BUY}_{w^{\prime}}(y)\left(e^{\prime}\right)
\end{array}\right]
\end{array}\right]}_{\text {modal component }}]
\end{aligned}
$$

We discuss the second meaning component. Alonso-Ovalle \& Menéndez-Benito (2018) assume that any volitional event $\mathbf{e}$ is caused by a decision to act on the part of its agent $\left(d_{\mathbf{e}}\right)$, that $d_{\mathbf{e}}$ is part of the preparatory stage of $\mathbf{e}$ (see Grano 2011), and that a decision to act $d_{\mathbf{e}}$ by agent $a$ establishes a goal, which is fulfilled by events 

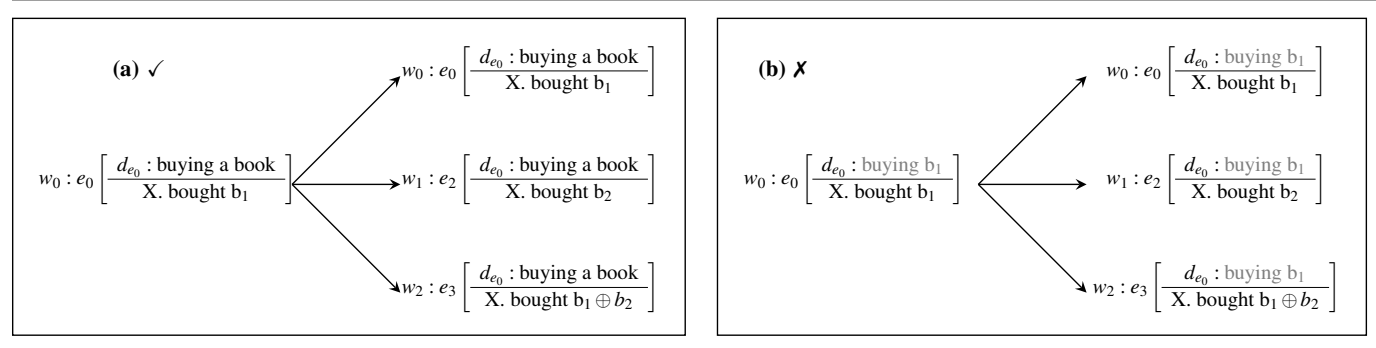

Figure 1 Actual decisions consistent (a) and inconsistent (b) with random choice modal component. $\left({ }^{*} \mathrm{BOOK}_{w}=\left\{b_{1}, b_{2}, b_{1} \oplus b_{2}\right\}\right)$

performed by $a$. We follow them in assuming that when $\mathbf{e}$ is a volitional event with no informational content, $f(\mathbf{e})$ yields a set of worlds that have a duplicate of $d_{\mathbf{e}}$ and where the goal established by $d_{\mathbf{e}}$ is fulfilled (by an event with the same spatiotemporal location as $e$ ). The modal component in (42) provides information about the actual decision: it looks at the worlds compatible with Xun's actual decision where that decision is fulfilled and conveys that for any book or group of books $y$, there is a world compatible with Xun's actual decision where that decision is fulfilled and $y$ is bought. For this to be the case, Xun's actual decision must be one that does not discriminate between types of books, since a decision to buy one particular book or group of books cannot be fulfilled by buyings of other books (see fig. 1). This captures the random choice interpretation: the sentence in (40a) excludes the possibility that the agent decided to only buy one particular book or one particular group of books. ${ }^{12}$

Now, recall that yalnhej-DPs as objects of non-volitional verbs, as in (21), cannot have a random choice interpretation. This follows from the current set-up: if the anchor is co-bound with the event argument, as in (43b), $f$ cannot project from its argument $\mathbf{e}$ the agent's decision of $\mathbf{e}$, since when the verbal predicate does not describe a volitional event, e will not contain a decision subevent.

a. [ Yalnhej tas tekal] ix-s-nib'-ej waj Xun. YALNHEJ what dish PFV-A3-like-DTV CLF Xun

'Xun liked some dish or group of dishes, I don't know which one, maybe all.' / Not: 'Xun liked a dish at random.' (repeated from (21))

b. $\lambda w_{1} \exists_{e} \operatorname{Xun}\left[\mathrm{v}^{0}\left[\mathrm{vp} \lambda e_{1}\left[\left[\left[\right.\right.\right.\right.\right.$ yalnhej what dish $\left.e_{1}\right] \lambda x_{1}$ liked $\left.\left.\left.\left.t_{1}\right] e_{1}\right] w_{1}\right]\right]$

12 Unless he decides to buy them all, as discussed on page 15 below. 

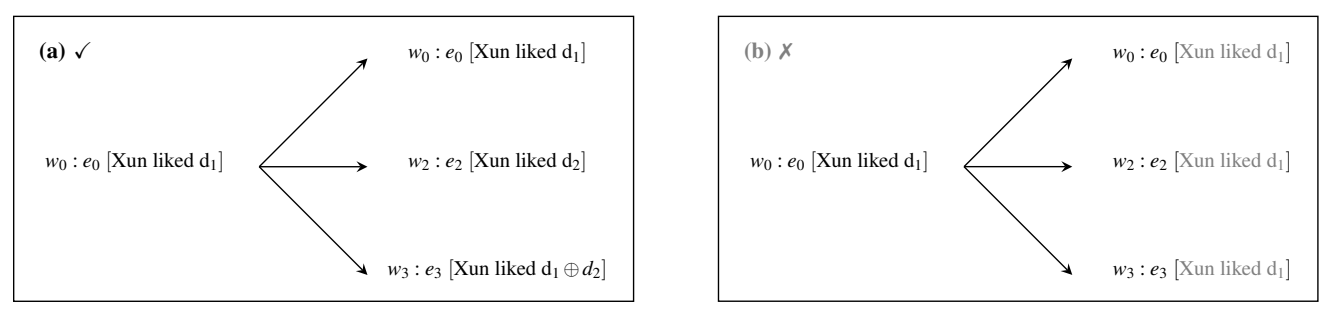

Figure 2 Belief states (a) compatible, (b) incompatible with epistemic content.

\subsection{Epistemic interpretations}

We hypothesize that yalnhej DPs have a second option: to project their domain from the assertion made by the speaker of the utterance, as suggested in Hacquard 2006 for non-root auxiliaries. To illustrate, we assume that event variables can be restricted such that they only range over the assertion, by using the predicate of events in (44).

(44) $\llbracket A S S E R T I O N \rrbracket^{c}=\lambda e_{v}: e$ is the assertion made by the speaker of $c . e$

When the event argument of the yalnhej DP is restricted to the assertion, it cannot be cobound with the event argument of the VP, as in (45): in (45), ASSERTION $\left(e_{1}\right)$ requires $e_{1}$ to be an assertion, but for $e_{1}$ to be in the relation denoted by like, $e_{1}$ cannot be an assertion. Alternatively, the event argument can be left free, in which case $f$ can project from the assertion, as in (46), deriving the proposition in (47).

$$
\begin{aligned}
& \lambda w_{1} \exists_{e}\left[\operatorname{Xun}\left[\mathrm{v}^{0}\left[\mathrm{vp} \lambda e_{1}\left[\left[\left[y \text { alnhej what dish } \operatorname{ASSERT}{ }^{\prime} \mathrm{N}\left(e_{1}\right)\right] \lambda x_{1} \text { liked } t_{1}\right] e_{1}\right] w_{1}\right]\right]\right. \\
& \lambda w_{1} \exists_{e}\left[\operatorname{Xun}\left[\mathrm{v}^{0}\left[\mathrm{vp} \lambda e_{1}\left[\left[\left[y a l n h e j \text { what dish } \operatorname{ASSERT}{ }^{\prime} \mathrm{N}\left(e_{2}\right)\right] \lambda x_{1} \text { liked } t_{1}\right] e_{1}\right] w_{1}\right]\right]\right. \\
& \lambda w . \exists e[\underbrace{\exists x\left[\begin{array}{l}
\operatorname{LIKE}_{w}(x)(e) \& \\
{ }^{*} \operatorname{DISH}_{w}(x) \& \\
\left.\operatorname{EXPERIENCER}_{\mathrm{XPUN}}\right)(e)
\end{array}\right]}_{\text {existential component }} \& \underbrace{\forall y\left[\begin{array}{l}
{ }^{*} \operatorname{DISH}_{w}(y) \rightarrow \\
\exists w^{\prime} \in f\left(\mathbf{e}_{\mathrm{ASSERT}}\right) \\
\exists e^{\prime}\left[\begin{array}{l}
e^{\prime} \approx e \& \\
\operatorname{LIKE}_{w^{\prime}}(y)\left(e^{\prime}\right)
\end{array}\right]
\end{array}\right]}_{\text {modal component }}]
\end{aligned}
$$

When $f$ projects from the assertion (and, more generally, from an eventuality with informational content), we assume that it yields the set of worlds compatible with the speaker's beliefs (more generally, the holder of the information state) (cf. Hacquard 2006). The modal component is compatible with situations where, as far as the speaker believes, Xun might have liked any dish or group of dishes, and incompatible with situations where the speaker knows that Xun didn't like all dishes and knows which dish or groups of dishes Xun liked (see figure 2 at the top of this page). 
Modality in the nominal domain
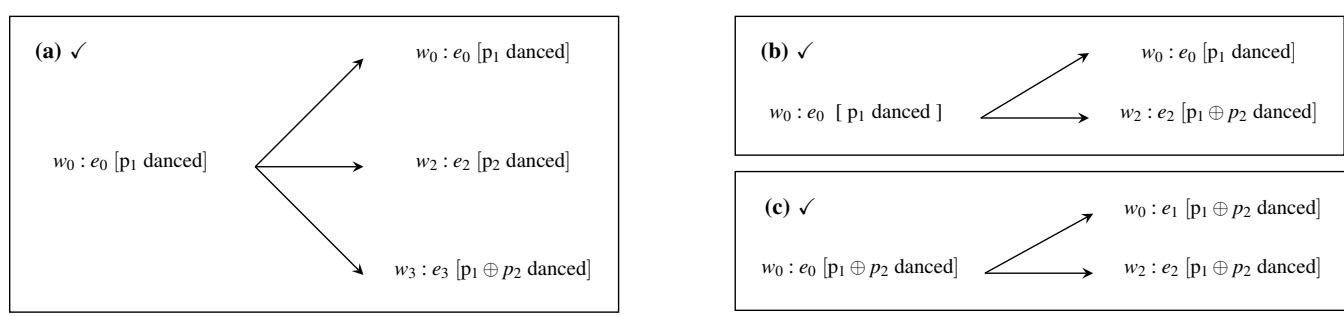

Figure 3 Degrees of ignorance

When yalnhej DPs are in subject position, we assume their event anchors are too high to be cobound with the VP event argument. In such cases, the modal anchor is necessarily free, and thus restricted to refer to the assertion (ignoring cases where yalnhej-DPs are embedded under external modals, discussed in §3.3).

a. [ Yalnhej mach ] ix-chanhalw-i.

YALNHEJ who PFV-dance-IV

'A person or group of people danced, I don't know who, maybe all did.'

b. $\lambda w_{1} \exists_{e}\left[\right.$ yalnhej what person $\left.\operatorname{ASSERT}{ }^{\prime} \mathrm{N}\left(e_{2}\right)\right] \lambda_{1}\left[t_{1}\left[\mathrm{Ag}^{0}\left[{ }_{\mathrm{vP}} \lambda e_{1}\left[\left[\right.\right.\right.\right.\right.$ danced $\left.\left.\left.\left.\left.e_{1}\right] w_{1}\right]\right]\right]\right]$

$$
\lambda w . \exists e[\underbrace{\exists x\left[\begin{array}{l}
\operatorname{DANCE}_{w}(x)(e) \& \\
{ }^{*} \operatorname{PEOPLE}_{w}(x) \& \\
\operatorname{AGENT}(x)(e)
\end{array}\right]}_{\text {existential component }} \& \underbrace{\forall y\left[\begin{array}{l}
{ }^{*} \operatorname{PEOPLE}_{w}(y) \rightarrow \exists w^{\prime} \in f\left(\mathbf{e}_{\text {ASSERT'N }}\right) \\
\exists e^{\prime}\left[\begin{array}{l}
e^{\prime} \approx e \text { \& } \operatorname{AGNT}(y)(e) \& \\
\operatorname{DANCE}_{w^{\prime}}(y)\left(e^{\prime}\right)
\end{array}\right]
\end{array}\right]}_{\text {modal component }}]
$$

The epistemic modal component in (49) is compatible with different degrees of ignorance: complete ignorance (figure 3 (a) below), partial ignorance (figure 3 (b)), and no ignorance, if all individuals satisfy the existential claim (figure 3 (c)). This captures the Chuj consultant's comment in (18), repeated in (50), and the fact that the random choice interpretation of (40a) is compatible with the agent deciding to buy all books.

(50) "When you hear (48b), you could conclude that just some people danced (and the speaker doesn't know who), or simply that everybody danced."

\subsection{Prediction: 'Harmonic' interpretations}

We conclude with a prediction. If other modal expressions project their possibilities from an anchor, then the modal anchors of yalnhej-DPs that are embedded under external modals could be coindexed with the modal anchor of these external modals, 
deriving interpretations (which Alonso-Ovalle \& Menéndez-Benito (2018) call 'harmonic') where the external modal and the yalnhej DP share a modal domain.

This prediction is borne out both for modal expressions with volitional anchors and for those with non-volitional anchors (doxastic or epistemic attitudes). Consider, for instance, the imperative sentence in (51). First, the sentence can convey the (nonharmonic) interpretation that the addressee must grab a card at random. Assuming a modal analysis for the imperative, and assuming that the imperative modal projects from an anchor, this interpretation is derived from letting the yalhnej DP project its modal domain locally, as in (52):

[Yal-nhej tas karta'-il ] tz-a-yam-a'!

YALNEHJ what card-NML IPFV-A2S-grab-TV

Possible interpretation: 'Grab a card at random!' (felicitous given (33))

$\lambda w_{1} \square_{e_{2}} \exists_{e}\left[\right.$ you $\left[\operatorname{Ag}\left[\mathrm{vP} \lambda e_{1}\left[\left[\right.\right.\right.\right.$ yalnhej what card NP $\left.\left.\left.\left.\left.e_{1}\right] \lambda x_{1} \operatorname{grab} t_{1}\right] e_{1}\right] w_{1}\right]\right]$

Assuming projection for the yalnhej DP from the event argument as in the random choice cases discussed above (and assuming that $e_{2}$ refers to the order), the predicted truth-conditions convey that in every permitted world, the addressee makes an indiscriminate decision to grab a card-any card.

$$
\lambda w . \forall w^{\prime} \in f_{\text {imp }}\left(\mathbf{e}_{2}\right) \exists e\left[\exists x\left[\begin{array}{l}
\operatorname{GRAB}_{w^{\prime}}(x)(e) \& \\
{ }^{*} \operatorname{CARD}_{w^{\prime}}(x) \& \\
\operatorname{AGENT}_{\operatorname{Can}(e)}(e)
\end{array}\right] \& \forall y\left[\begin{array}{l}
{ }^{*} \operatorname{CARD}_{w^{\prime}}(y) \rightarrow \\
\exists w^{\prime \prime} \in f(e) \\
\exists e^{\prime}\left[\begin{array}{l}
e^{\prime} \approx e \& \\
\operatorname{GRAB}_{w^{\prime \prime}}(y)\left(e^{\prime}\right)
\end{array}\right]
\end{array}\right]\right]
$$

The same sentence can convey a second 'harmonic' interpretation: the sentence is appropriate in the context in (54). Under this interpretation, the sentence conveys that the addressee is required to grab a card, and that any card is a permitted possibility for the speaker - the addressee does not need to grab a card at random:

At the beginning of a boardgame, players must select any card they want from the game. It's the first time you play, and you ask me what you need to do. $(51)=\checkmark$

This type of harmonic interpretation is also detected with uno cualquiera: the sentence in (55) is compatible with the speaker wanting the addressee to pick any book they want, and not necessarily them picking one at random.

¡Coge un libro cualquiera!

grab a book CUALQUIERA

'Grab a book, any book!'

(Alonso-Ovalle \& Menéndez-Benito 2018) 
Alonso-Ovalle \& Menéndez-Benito (2018) derive this interpretation by letting uno cualquiera project from a modal anchor coindexed to the modal anchor of the imperative, as yalnhej card does in (56). They assume, as we do, that the modal anchor of the imperative operator picks up an order (cf. Hacquard 2006 on performative modals) and that uno cualquiera projects its modal domain from that order by looking at the worlds consistent with the decision leading to that order where the order is obeyed. Following their approach, we can assume that the modal component yalnhej card in (56) invokes the worlds where the decision leading to the order is fulfilled. The resulting truth-conditions convey (i) that the addressee is required to pick a card, and (ii) that picking any card is compatible with the order. There is no requirement to pick a card at random.

$$
\begin{aligned}
& \lambda w_{1} \square_{e_{2}} \exists_{e}\left[\text { you }\left[\operatorname{Ag}\left[\mathrm{vp} \lambda e_{1}\left[\left[\text { yalnhej what card NP } e_{2}\right] \lambda x_{1} \operatorname{grab} t_{1}\right] e_{1}\right] w_{1}\right]\right] \\
& \lambda w . \forall w^{\prime} \in f_{\mathrm{imp}}\left(\mathbf{e}_{2}\right) \exists e\left[\exists x\left[\begin{array}{l}
\operatorname{GRAB}_{w^{\prime}}(x)(e) \& \\
{ }^{*} \operatorname{CARD}_{w^{\prime}}(x) \& \\
\operatorname{AGENT}(\operatorname{XUN})(e)
\end{array}\right] \& \forall y\left[\begin{array}{l}
{ }^{*} \operatorname{CARD}_{w^{\prime}}(y) \rightarrow \\
\exists w^{\prime} \in f\left(\mathbf{e}_{2}\right) \\
\exists e^{\prime}\left[\begin{array}{l}
e^{\prime} \approx e \& \\
\operatorname{GRAB}_{w^{\prime}}(y)\left(e^{\prime}\right)
\end{array}\right]
\end{array}\right]\right]
\end{aligned}
$$

Epistemic 'harmonic' interpretations are also possible, as in (58) below, which could be uttered by a speaker who (i) knows who danced at the party and (ii) knows that not all people danced:

Context: Xun thinks that some people danced at the party, but he doesn't know exactly who. As far as he can tell, it could be anyone.

Tz-s-na' waj Xun to [yalnhej mach ] ix-chanhalw-i t'a k'inh. PFV-A3-think CLF Xun C YALNHEJ who PFV-dance-IV PREP party

'Xun thinks that a person or people danced, and any person is a possibility.'

Assuming projection of the attitude's modality from an anchor (Kratzer 2006), these can be treated as cases where the anchor of yalnhej is coindexed with the attitude's anchor. In these cases, $f$ could project from the modal anchor of the yalnhej DP the set of worlds consistent with Xun's belief state.

$$
\begin{aligned}
& \lambda w_{2} \text { X. bel. } w_{2}\left(e_{2}\right) \lambda w_{1} \exists_{e}\left[\operatorname{yalnhej~mach}\left(e_{2}\right)\right] \lambda_{1}\left[t_{1}\left[\operatorname{Ag}\left[\mathrm{vP} \lambda e_{1}\left[\left[\operatorname{danced} e_{1}\right] w_{1}\right]\right]\right]\right] \\
& \lambda w \cdot \forall w^{\prime} \in f_{\text {belief }}\left(\mathbf{e}_{2}\right) \exists e\left[\exists x\left[\begin{array}{l}
\operatorname{DANCE}_{w^{\prime}}(x)(e) \& \\
{ }^{*} \operatorname{PEOPLE}_{w^{\prime}}(x) \& \\
\operatorname{AGENT}(x)(e)
\end{array}\right] \& \forall y\left[\begin{array}{l}
{ }^{*} \operatorname{PEOPLE}_{w^{\prime}}(y) \rightarrow \\
\exists w^{\prime \prime} \in f\left(\mathbf{e}_{2}\right) \\
\exists e^{\prime}\left[\begin{array}{l}
e^{\prime} \approx e \& \operatorname{AG}(y)(e) \\
\& \mathrm{D}_{w^{\prime \prime}}(y)\left(e^{\prime}\right)
\end{array}\right]
\end{array}\right]\right]
\end{aligned}
$$

As shown in (61), this possibility is not attested for uno cualquiera, which cannot have epistemic interpretations in unembedded contexts, either. 
(61) Juan tiene que haber ido a ver una película cualquiera.

Juan must that have gone to see a film CUALQUIERA.

'Juan must have gone to see a movie at random.' / Not: 'Juan must have gone to watch a movie, any movie is a possibility for me.'

(Alonso-Ovalle \& Menéndez-Benito 2018)

\section{Conclusion}

We started this paper with two general questions about the crosscategorial nature of modality:

Q1. What modal flavours do DPs express?

Q2. How is the modal flavour of modal DPs determined?

With respect to the first question, we showed that, in the absence of external modals, the modal component of yalnhej-DPs can be epistemic or random choice. These modal flavours are common within the class of modal indefinites, however yalnhejDPs contrast with other modal indefinites in that the modal component seems to be truth-conditional. While there are clear parallels of the epistemic interpretation in the verbal domain, it is less clear whether there exist parallels of the random choice modal flavour outside of the nominal domain. Although random choice construals of modal auxiliaries seem to be inexistent, Martin \& Schäffer (2012) and Martin \& Schäfer (2017) discuss a type of main verb ('defeasible causatives') with a modal component that track agent goals. Perhaps, this is a point of cross-categorial parallelism between the nominal and verbal domain with respect to random choice modality.

As for the second question, we have seen that the type of modal flavour expressed by yalnhej-DPs correlates with their syntactic position. We captured this by assuming, in line with recent proposals for modal auxiliaries (e.g. Hacquard 2006, 2009, 2010; Alonso-Ovalle \& Menéndez-Benito 2018), that yalnhej-DPs project their modal domains from the value of an event argument.

Finally, we have also shown that yalnhej-DPs contrast with other modal indefinites in that the existential claim that they express does not convey an upper bound. This typological possibility has theoretical significance. In Chierchia 2013, the modal component of modal indefinites (derived via grammatical strengthening) is the consequence of a modal operator intervening to prevent the derivation of a contradictory implicature that involves an upper bound. Yalnhej-DPs convey a modal component, but no upper bound. 
Modality in the nominal domain

\section{References}

Aissen, Judith. 2017. Correlates of ergativity in Mayan. In Jessica Coon, Diane Massam \& Lisa Travis (eds.), Oxford Handbook of Ergativity, New York, NY: Oxford University Press.

Alonso-Ovalle, Luis \& Paula Menéndez-Benito. 2010. Modal indefinites. Natural Language Semantics 18(1). 1-31. https://doi.org/10.1007/s11050-009-9048-4

Alonso-Ovalle, Luis \& Paula Menéndez-Benito. 2011. Expressing indifference: Spanish un NP cualquiera. In Michael Ashton et al. (ed.), Semantics and Linguistic Theory Conference (SALT) 21, 333-347. Ithaca, NY: Cornell University. Alonso-Ovalle, Luis \& Paula Menéndez-Benito. 2015. Epistemic Indefinites: Exploring Modality beyond the Verbal Domain. Oxford: Oxford University Press.

Alonso-Ovalle, Luis \& Paula Menéndez-Benito. 2018. Projecting possibilities in the nominal domain: Spanish uno cualquiera. Journal of Semantics 35(1). 1-41. https://doi.org/10.1093/jos/ffx011

Arregui, Ana, María Luisa Rivero \& Andrés Salanova. 2017. Modality across Syntactic Categories. Oxford: Oxford University Press.

Brennan, Virginia. 1993. Root and Epistemic Modal Auxiliary Verbs: University of Massachusetts at Amherst PhD dissertation.

Buccola, Brian \& Andreas Haida. 2017. Expressing indifference in German. In Alexandre Cremers, Thom van Gessel \& Floris Roelofsen (eds.), The 21st Amsterdam Colloquium, vol. 21, 165-174.

Buenrostro, Cristina. 2009. Chuj de San Mateo Ixtatán. Mexico City: El Colegio de México.

Buenrostro, Cristina. 2013. La voz en Chuj de San Mateo Ixtatán. Mexico City: El Colegio de México PhD dissertation.

Buenrostro, Cristina. to appear. Apuntes sobre la marcación de número nominal en chuj. In Cristina Buenrostro (ed.), Estudios de Lengua y Cultura Chuj, Universidad Nacional Autónoma de México.

Chierchia, Gennaro. 2013. Logic in Grammar. Oxford: Oxford University Press.

Condoravdi, Cleo. 2015. Ignorance, indifference and individuation with wh- ever. In Luis Alonso-Ovalle \& Paula Menéndez-Benito (eds.), Epistemic Indefinites, 213-243. Oxford: Oxford University Press.

Coon, Jessica, Nico Baier \& Theodore Levin. 2021. Mayan agent focus and the ergative extraction constraint: Facts and fictions revisited. Language 97(1). 269-332. https://doi.org/10.1353/lan.2021.0019

Davis, Henry, Carrie Gillon \& Lisa Matthewson. 2014. How to investigate linguistic diversity: Lessons from the Pacific Northwest. Language 90(4). 180-226. https://doi.org/10.1353/lan.2014.0076

von Fintel, Kai. 2000. Whatever. In Brendan Jackson \& Tanya Matthews (eds.), 
Semantics and Linguistic Theory Conference, 27-40. Ithaca, NY: CLC Publications.

García Pablo, Gaspar \& Pascual Martín Domingo Pascual. 2007. Stzolalil SloloniSpaxtini heb' Chuj: Gramática Descriptiva Chuj. Guatemala: Academia de Lenguas Mayas de Guatemala.

Grano, Thomas. 2011. Mental action and event structure in the semantics of 'try'. In Neil Ashton, Anca Chereches \& David Lutz (eds.), Semantics and Linguistic Theory Conference (SALT) 21, 426-443. Ithaca, NY: Cornell University.

Hacquard, Valentine. 2006. Aspects of Modality: MIT PhD dissertation.

Hacquard, Valentine. 2009. On the interaction of aspect and modal auxiliaries. Linguistics and Philosophy 32(3). 279-315. https://doi.org/10.1007/s10988-0099061-6

Hacquard, Valentine. 2010. On the event relativity of modal auxiliaries. Natural Language Semantics 18(1). 79-114. https://doi.org/10.1007/s11050-010-9056-4

Hacquard, Valentine. 2011. Modality. In Klaus von Heusinger Claudia Maienborn \& Paul Portner (eds.), Semantics: An International Handbook of Natural Language Meaning, vol. 2, 1484-1515. Berlin: Mouton de Gruyter.

Hopkins, Nicholas. 1967. The Chuj Language. Chicago, IL: University of Chicago $\mathrm{PhD}$ dissertation.

Hopkins, Nicholas A. 2021. Chuj (Mayan) Narratives: Folklore, History, and Ethnography from Northwestern Guatemala. Boulder, CO: University of Colorado.

Jacobson, Pauline. 1995. On the quantificational force of English free relatives. In Angelika Kratzer Emmon Bach, Eloise Jelinek \& Barbara H. Partee (eds.), Quantification in Natural Languages, 451-486. Dordrecht: Kluwer.

Kotek, Hadas \& Michael Yoshitaka Erlewine. 2019. Wh-indeterminates in Chuj (Mayan). Canadian Journal of Linguistics 64(1). 62-101. https://doi.org/10.1017/cnj.2018.25

Kratzer, Angelika. 1981. The notional category of modality. In H.J. Eikmeyer \& H. Rieser (eds.), Worlds, Words, and Contexts, 38-74. Berlin and New York: de Gruyter. Reprinted in Kratzer (2012), chapter 3.

Kratzer, Angelika. 1996. Severing the external argument from its verb. In Johan Rooryck \& Laurie Zaring (eds.), Phrase Structure and the Lexicon, 109-137. Dordrecht: Kluwer Academic Publishers.

Kratzer, Angelika. 2006. Decomposing attitude verbs. talk at the Hebrew University of Jerusalem honoring Anita Mittwoch on her 80th birthday. Ms. McGill. http://www.semanticsarchive.net/Archive/DcwY2JkM/attitude-verbs2006.pdf.

Kratzer, Angelika. 2012. Modals and Conditionals. New and Revised Perspectives. Oxford: Oxford University Press.

Kratzer, Angelika. 2013. Modality for the 21st century. In Stephen R. Ander- 
Modality in the nominal domain

son, Jacques Moeschler \& Fabienne Raboul (eds.), The Language-Cognition Interface, 179-199. Librairie Droz.

Kratzer, Angelika \& Junko Shimoyama. 2002. Indeterminate pronouns: The view from Japanese. In Y. Otsu (ed.), The 3rd Tokyo Conference on Psycholinguistics, $1-25$.

Martin, Fabienne \& Florian Schäfer. 2017. Sublexical modality in defeasible causative verbs. In Ana Arregui, María Luisa Rivero \& Andrés Salanova (eds.), Modality Across Syntactic Categories, 87-108. Oxford University Press.

Martin, Fabienne \& Florian Schäffer. 2012. The modality of 'offer' and other defeasible causative verbs. In N. Arnett \& R. Bennett (eds.), West Coast Conference on Formal Linguistics (WCCFL) 30, 248-258. Somerville, MA: Cascadilla Press.

Mateo Pedro, Pedro \& Jessica Coon. 2017. Chuj oral tradition collection of Pedro Mateo Pedro and Jessica Coon. Archive of Indigenous Languages of Latin America: University of Texas Austin.

Matthewson, Lisa. 2004. On the methodology of semantic fieldwork. International Journal of American Linguistics 70(4). 369-415. https://doi.org/10.1086/429207

Maxwell, Judith. 1981. How to talk to people who talk chekel 'different': The Chuj (Mayan) solution. Chicago, IL: University of Chicago PhD dissertation.

Piedrasanta, Ruth. 2009. Los Chuj, unidad y rupturas en su espacio. Guatemala City, Guatemala: Amrar Editores.

Poole, Ethan. 2017. Movement and the Semantic Type of Traces: University of Massachusetts at Amherst PhD dissertation.

Royer, Justin. 2020. Headless relative clauses in Chuj. In Ivano Caponigro, Harold Torrence \& Roberto Zavala (eds.), Headless Relative Clauses in Mesoamerican Languages, 327-361. Oxford University Press.

Royer, Justin, Pedro Mateo Pedro, Elizabeth Carolan, Jessica Coon \& Matal Torres. to appear. Atz'am k'ik' atz'am: The story of Xuwan and a grammatical sketch of Chuj. Tlalocan.

Luis Alonso-Ovalle

Department of Linguistics

1085 Avenue du Docteur Penfield

Montréal, Québec, Canada H3A1A7

luis.alonso-ovalle@mcgill.ca
Justin Royer Department of Linguistics 1085 Avenue du Docteur Penfield Montréal, Québec, Canada H3A1A7 justin.royer@mail.mcgill.ca 